\title{
Diagnostic reliability of clinical signs in cows with traumatic reticuloperitonitis and abomasal ulcers
}

\author{
Ueli Braun* ${ }^{*}$, Karl Nuss, Sonja Warislohner, Christina Reif, Carina Oschlies and Christian Gerspach
}

\begin{abstract}
Background: Clinical signs of traumatic reticuloperitonitis and abomasal ulcer are often similar making the disorders difficult to differentiate. The goal of our study was to compare the frequency of individual clinical signs of cows with traumatic reticuloperitonitis and cows with abomasal ulcers and determine their diagnostic significance. The frequency of the findings "rectal temperature, heart rate, respiratory rate, demeanour, signs of colic, arched back, abdominal guarding, bruxism, scleral vessels, rumen motility, foreign body tests, percussion auscultation, swinging auscultation and faecal colour" of cows with traumatic reticuloperitonitis (TRP, $n=503)$ and cows with type 1 (U1, $n=94)$, type 2 $(\mathrm{U} 2, n=145)$, type $3(\mathrm{U} 3, n=60)$, type $4(\mathrm{U} 4, n=87)$ and type $5(\mathrm{U} 5, n=14)$ abomasal ulcer were compared, and the reliability indices "diagnostic sensitivity and specificity, positive and negative predictive values and positive likelihood ratio" were calculated. A total of 182 healthy cows served as controls (control group).

Results: None of the cows in the control group had colic, rumen atony or melena, $99 \%$ had no abnormalities in demeanor and appetite and did not have a rectal temperature of $\leq 38.6$ or $>40.0^{\circ} \mathrm{C}$, a heart rate $>100 \mathrm{bpm}$ or a respiratory rate $>55$ breaths per min, and $95 \%$ did not have an arched back or bruxism. The control group was therefore ideal for comparative purposes. Many signs such as mild increase in rectal temperature, scleral congestion and positive foreign body test were non-diagnostic because they occurred in healthy as well as in ill cows. Likewise, differentiation of cows with TRP and abomasal ulcer was not possible based on single clinical variables; a detailed history and a comprehensive assessment of all clinical findings were required for this.
\end{abstract}

Conclusions: The findings of the present study serve as a guide for the veterinarian in the differentiation of cows with traumatic reticuloperitonitis and abomasal ulcer.

Keywords: Cattle, Traumatic reticuloperitonitis, Abomasal ulcus, Sensitivity, Specificity, Predictive values, Likelihood ratio $_{+}$

\section{Background}

Traumatic reticuloperitonitis (TRP) and abomasal ulcer are important diseases, and together with displaced abomasum, belong to the most common gastrointestinal disorders of dairy cows. Traumatic reticuloperitonitis may be acute or chronic $[1,2]$ and abomasal ulcers are classified

\footnotetext{
* Correspondence: ubraun@vetclinics.uzh.ch

Department of Farm Animals, Vetsuisse-Faculty, University of Zurich,

Winterthurerstrasse 260, CH-8057 Zurich, Switzerland
}

as types 1 (U1), 2 (U2), 3 (U3), 4 (U4) or 5 (U5) [3-8]. U1 is a non-perforated ulcer of the abomasal mucosa associated with minimal haemorrhage, whereas $\mathrm{U} 2$ involves the erosion of a large blood vessel and is therefore associated with massive intraluminal haemorrhage. U3 is a perforated ulcer accompanied by localised peritonitis, U4 is a perforated ulcer characterised by generalised peritonitis and U5 is an ulcer that has perforated into the omental bursa causing omental bursitis. Sometimes more than one type of abomasal ulcer occurs in the same cow [9]. The clinical

(c) The Author(s). 2020 Open Access This article is licensed under a Creative Commons Attribution 4.0 International License, which permits use, sharing, adaptation, distribution and reproduction in any medium or format, as long as you give appropriate credit to the original author(s) and the source, provide a link to the Creative Commons licence, and indicate if changes were made. The images or other third party material in this article are included in the article's Creative Commons licence, unless indicated otherwise in a credit line to the material. If material is not included in the article's Creative Commons licence and your intended use is not permitted by statutory regulation or exceeds the permitted use, you will need to obtain permission directly from the copyright holder. To view a copy of this licence, visit http://creativecommons.org/licenses/by/4.0/ The Creative Commons Public Domain Dedication waiver (http://creativecommons.org/publicdomain/zero/1.0/) applies to the data made available in this article, unless otherwise stated in a credit line to the data. 
findings of cows with TRP [10], U1 [11], U2 [12], U3 [13], U4 [14] and U5 [8] were recently described in detail, and overviews of older studies of cows with TRP [10] and of cows with abomasal ulcer [11] were also reported. A common thread running through all those studies was that the different disorders were often characterised by similar clinical manifestations $[8,10-14]$. However, the frequency with which the clinical signs occured varied widely among the different disorders. The prognosis also varied and was usually favourable in cows with TRP [10] or U2 [12] but was hopeless in cows with U4 [14] or U5 [8]. Treatment of these diseases also differed, for example cows with TRP received antibiotics and a magnet [15], whereas recovery of cows with U2 usually required a blood transfusion [12]. If a correct diagnosis was possible based on the clinical examination, the reliability of the prognosis would increase allowing better decision-making with regard to treatment or euthanasia. To aid in the decision-making process, the frequencies of specific clinical findings were compared among cows with TRP, U1, U2, U3, U4 and U5, and the diagnostic sensitivity and specificity, the positive and negative predictive values and the likelihood ratio ${ }_{+}$ were calculated. These indices aid the clinician in differentiating the above-mentioned diseases and facilitate a diagnosis and the decision to treat or euthanase.

\section{Methods \\ Animals}

A total of 1085 cows including 182 healthy controls, 503 cows with TRP, 94 cows with U1, 145 cows with U2, 60 cows with U3, 87 cows with U4 and 14 cows with U5 were used. All animals were privately owned and transported to the Veterinary Teaching Hospital of the University of Zurich for clinical examination. The sample size differed between groups and was dictated by the case load, which varied depending of the incidence of the disease in the population.

Tentative and definitive diagnosis of TRP and type 1, 2, 3, 4 or 5 abomasal ulcer

The tentative diagnosis of TRP was based on clinical findings that included abnormal general demeanour, fever, reduced rumen motility, positive foreign body test, poorly digested faeces and spontaneous signs of pain such as arching of the back, bruxism and grunting. The final diagnosis of TRP was based on radiographic evidence of a foreign body that penetrated or perforated the reticular wall or was seen outside of the reticulum (225 cattle), ultrasonographic changes of the reticular wall (403 cattle), laparoruminotomy and/or postmortem examination. In all cattle, the definitive diagnosis of TRP was based on more than one criterion. Cattle with TRP that had concomitant diseases causing anterior abdominal or caudal thoracic pain were excluded; this included 27 cows with bronchopneumonia and 24 cows with abomasal ulcers. In 449 of 470 cows $(95.5 \%)$ with a complete history, the illness was acute with a maximum duration of 4 weeks and in 21 cows $(4.5 \%)$ it was chronic with a duration of more than 4 weeks.

Type-1 ulcers were suspected in cows in the first weeks after calving with a poor appetite (non-specific indigestion characterised by fluctuations in appetite, moderate tympany, colic and dark, often soft to liquid faeces) when correction of possible underlying disorder such as displaced abomasum did not have the expected result. The final diagnosis of U1 was based on the results of laparotomy, when focal thinning of the abomasal wall was seen or an ulcer could be palpated, and/or finding an ulcer at postmortem examination. Cows in which U1 was accompanied by U2, U3, U4 or U5 were excluded from the study.

The diagnosis of U2 was based on typical manifestations of intraluminal haemorrhage in the anterior gastrointestinal tract including tachycardia, pale mucous membranes, dark or black manure, low haematocrit and the presence of blood in the faeces when abomasal volvulus, intussusception, haemorrhagic bowel syndrome, haemorrhage in the pharyngeal region and pulmonary haemorrhage could be ruled out as the cause of blood loss. In 100 of 103 (97\%) cows, a test to detect occult blood in the faeces was positive. In seven cows, exploratory right-flank laparotomy was necessary to make a diagnosis. The diagnosis was confirmed at postmortem examination in cows that died or were euthanased.

Type- 3 abomasal ulcer was suspected in cows with nonspecific clinical signs resembling TRP when other diseases associated with localised peritonitis such as TRP could be ruled out by radiography and ultrasonography. A final diagnosis of U3 was made when exploratory laparotomy showed fibrinous adhesions between the abomasum and the peritoneum and a reticular foreign body could be ruled out, or when the ulcer was detected at postmortem examination.

A tentative diagnosis of U4 was made in cows with clinical signs associated with generalised peritonitis such as tachycardia, tachypnoea, fever, congested scleral vessels, pale and muddy mucous membranes, decreased skin surface temperature, spontaneous grunting, abdominal guarding, diarrhea and reduction in the normally negative intraabdominal pressure on rectal examination. The final diagnosis of U4 was based in all cows on the results of postmortem examination.

A tentative diagnosis of U5 was made in cows with clinical signs of subacute to chronic peritonitis such as obtunded demeanour, indigestion, abdominal guarding, rumen atony and fever and ultrasonographic evidence of localised or generalised peritonitis. The final diagnosis of U5 was based on the results of postmortem examination 
when a perforated abomasal ulcer accompanied by omental bursitis was seen.

For U2, U3, U4, U5: No cases were excluded.

The control cows consisted of 182 healthy cows that were the offspring of cows with BSE and therefore referred by the Federal Veterinary Office BVET Switzerland to our clinic for examination. All the cows had a history of being healthy and were examined and monitored for demeanour, appetite, urination and defecation for several days. Although several cows had one abnormality, such as increased rectal temperature, increased heart rate, scleral congestion or reduced rumen motility, they were considered healthy based on all the variables monitored daily.

There were no other inclusion or exclusion criteria for including animals in the study.

\section{Treatment and response to treatment}

Initial treatment of 503 cows with TRP was selected on the basis of radiographic findings at the time of admission [15]. Cattle with a foreign body attached to a magnet were treated conservatively (amoxicillin or penicilline G procaine, slow intravenous drip infusion of a solution containing sodium chloride and glucose), and cattle with radiographic evidence of a foreign body (non-penetrating, penetrating or perforating) were treated with antibiotics and a magnet. Radiographic examination was repeated on the following day and the results were used to guide subsequent treatment. Conservative treatment was continued when the foreign body was completely attached to the magnet and another radiograph was made. In cases where the foreign body was not in contact with the magnet or was still penetrating or perforating the reticulum, rumenotomy was carried out. Of 232 cattle, 191 (82\%) were treated successfully and discharged and 41 did not respond to treatment and were euthanased. Surgical treatment was successful in 186 (90\%) of 206 cases.

Seventy-eight (83\%) cows with U1 were euthanased immediately after the initial examination, during laparotomy or after unsuccessful treatment (correcting of the main clinical problem, intravenous administration of a solution containing sodium chloride and glucose, flunixin meglumine or metamizole), and eight (8.5\%) cows died, and all underwent a postmortem examination [11]. Eight (8.5\%) cows were discharged and six of these made a complete recovery.

Ten of 145 cows with U2 were euthanased immediately after, or died during, the initial examination, and treatment was started in 135 cows [12]. Treatment included blood transfusion, sodium chloride and glucose solution, calcium borogluconate, vitamin $\mathrm{C}$ and metamizole. Ninety-one (67\%) of the 135 treated cows recovered and were discharged after a mean hospitalisation period of 9 days, and 44 cows (33\%) failed to respond to treatment and were euthanased or died.
Forty-eight of 60 (80\%) cows with U3 were euthanased immediately after the initial examination, during laparotomy or after unsuccessful treatment (solution of sodium chloride and glucose administered via an indwelling jugular catheter, antibiotics, metamizole or flunixin) [13]. Twelve (20\%) cows, that were treated, were discharged from the clinic.

Fifty-four of 87 (62\%) cows in which U4 was diagnosed were euthanased immediately except for a few that died during the examination [14]. Twelve (14\%) cows underwent right flank exploratory laparotomy to confirm the diagnosis and all were euthanased because of generalised peritonitis. The cows with an unclear diagnosis received a continuous intravenous infusion of a sodium chloride and glucose solution, antibiotics and an NSAID. Six cows died after the start of treatment and the remaining 15 were euthanased after 2 to 4 days because of deterioration in condition.

Eight of 14 (57\%) cows with U5 were treated (see U4) unsuccessfully and euthanased thereafter [8]. Six cows were euthanased immediately after the initial examination.

\section{Euthanasia}

Euthanasia was done with pentobarbital (Esconarkon, Streuli Pharma), $80 \mathrm{mg} / \mathrm{kg}$ body weight intravenously.

\section{Analysis of clinical variables}

The clinical findings of the controls [16] and the cows with TRP [10], U1 [11], U2 [12], U3 [13], U4 [14]) and U5 [8] have been described in detail. The variables demeanour, rectal temperature, heart rate, respiratory rate, colic, arched back, abdominal guarding, mucous membrane colour, congestion of scleral vessels, bruxism, rumen motility, pain response to foreign body tests, positive percussion and simultaneous auscultation also called percussion auscultation (produces a tympanic sound or metallic ping) and ballottement and simultaneous auscultation also referred to as swinging auscultation (produces splashing sounds followed by a bell-like echo) on the right side and faecal colour were analysed. The following reference intervals, defined previously [17] and modified slightly, were used for the metric variables: rectal temperature, 38.6$39.0^{\circ} \mathrm{C}$; heart rate, $60-80$ beats $/ \mathrm{min}(\mathrm{bpm})$ and respiratory rate, $15-35$ breaths/min.

\section{Statistical analysis}

The program SPSS Version 25 was used. The ShapiroWilk test was used to test the metric variables rectal temperature and heart and respiratory rates for normality. Because the data were non-normal, the medians and 25th and 75th percentiles were calculated. The medians underwent one-factor analysis of variance and pair-wise comparison using the Kruskal-Wallis test. Frequency distributions of all variables were calculated for the 
controls and 6 disease groups. The values of all variables were divided into appropriate ranges (for instance the rectal temperature; $<38.5^{\circ} \mathrm{C}, 38.6$ to 39.0 and $>39.0^{\circ} \mathrm{C}$ ) and differences between ranges were analysed using the chisquare and the Bonferroni post-hoc tests. A $P$-value $<0.05$ was considered significant. For each variable, the diagnostic sensitivity $(a /[a+c])$, the diagnostic specificity $(d /[b+$ d]), the positive likelihood ratio $\left(\mathrm{LR}_{+}\right.$, sensitivity/[1-specificity]), the positive predictive value $(a /[a+b])$ and the negative predictive value $(d /[c+d])$ were calculated $(a$, true positive; $b$, false positive; $c$, false negative; $d$, true negative) [18]. A false positive result was an abnormal finding in a control cow and a false negative result was a normal finding in a cow with TRP or abomasal ulcer.

\section{Results}

\section{Rectal temperature}

The median rectal temperatures ranged from 38.9 to $39.1^{\circ} \mathrm{C}$ and did not differ among groups (Table 1). The rectal temperature was in the reference interval $\left(38.6\right.$ to $39.0^{\circ} \mathrm{C}$, Table 2, Fig. 1) in $57 \%$ of the controls. With the exception of cows with U1 and U5, there were significantly fewer ill cows with a rectal temperature in the reference interval compared with controls. Eleven percent of controls had a temperature below the reference interval, and in $1 \%$ the temperature was $\leq 38.0^{\circ} \mathrm{C}$. Significantly more cows with TRP (25\%), U2 (32\%) and U4 (35\%) had a rectal temperature $\leq 38.5{ }^{\circ} \mathrm{C}$ compared with controls. The $\mathrm{LR}_{+}$for a rectal temperature $\leq 38.0^{\circ} \mathrm{C}$ was 14 for cows with $\mathrm{U} 2$ and U5 and 17 for cows with U4 (Table 3). Rectal temperatures $>39.0,>39.5$ and $>40.0^{\circ} \mathrm{C}$ occurred in 32,6 and $1 \%$ of controls, and $23 \%$ of cows with $\mathrm{U} 4$ had a rectal temperature > $39.5^{\circ} \mathrm{C}$, which was significantly different from the controls.

\section{Heart rate}

Cows with TRP, U1, U2, U3 and U4 had median heart rates of 76 to 108 beats per min (bpm), which was significantly higher than in controls $(72 \mathrm{bpm}$, Table 1$)$.
Seventy-six percent of controls had a heart rate in the reference interval from 60 to $80 \mathrm{bpm}$ (Table 2 and Fig. 2) compared with $48,10,45$ and $30 \%$ in cows with U1, U2, $\mathrm{U} 3$ and U4, respectively, which was significantly lower compared with controls. The percentage of control cows with heart rates $>80,>100$ and $>120 \mathrm{bpm}$ were 15,1 and $1 \%$. Heart rates $>80 \mathrm{bpm}$ were significantly more common in cows with U1 (49\%), U2 (90\%), U3 (55\%) and U4 (68\%) than in controls; the difference between cows with U2 and those with other illnesses was significant. The corresponding differences for heart rates of $>$ 100 and $>120 \mathrm{bpm}$ were similar. The LRs $s_{+}$for a heart rate $>100 \mathrm{bmp}$ in cows with abomasal ulcers ranged from 15 to 78 (Table 3), and the positive predictive values for a heart rate $>100 \mathrm{bpm}$ in ill cows ranged from 83 to $98 \%$.

\section{Respiratory rate}

The median respiratory rates of cows with U1, U2 and U4 were significantly higher than those of the controls (Table 1). Eighty-five percent of controls had a respiratory rate in the reference interval from 15 to 35 breaths/ min (Table 2 and Fig. 3) compared with 64, 63 and 62\% in cows with U2, U3 and U4, which was significantly lower. The percentages of control cows with respiratory rates $>35,>45$ and $>55$ breaths $/$ min were 15,2 and $1 \%$, respectively. Respiratory rates $>35$ breaths $/$ min occurred significantly more often in cows with TRP (23\%), U1 (29\%), U2 (36\%), U3 (37\%), U4 (38\%) and U5 (36\%) than in controls. The $\mathrm{LRs}_{+}$for a respiratory rate $>55$ breaths/min in cows with U1, U2, U3 and U4 ranged from 12 to 30, and the positive predictive value for all ill cows ranged from 80 to $92 \%$ (Table 3 ).

\section{Demeanour}

The demeanour was abnormal in $1 \%$ of the controls (Table 2) compared with 87 to $100 \%$ in the ill cows, which was significant. The $\mathrm{LR}_{+}$for abnormal demeanour

Table 1 Rectal temperature and heart and respiratory rates in healthy control cows, cows with traumatic reticuloperitonitis (TRP) and cows with type 1 (U1), type 2 (U2), type 3 (U3), type 4 (U4) or type 5 (U5) abomasal ulcer (medians, 25 and $75 \%$ percentiles in brackets)

\begin{tabular}{|c|c|c|c|c|c|c|c|}
\hline Variable & $\begin{array}{l}\text { Controls }(n= \\
182)\end{array}$ & $\operatorname{TRP}(n=500)$ & U1 $(n=93)$ & U2 $(n=144)$ & U3 $(n=60)$ & $\cup 4(n=86)$ & U5 $(n=13)$ \\
\hline Rectal temperature $\left({ }^{\circ} \mathrm{C}\right)$ & $38.9(38.7-39.2)$ & $\begin{array}{l}39.0(38.5- \\
39.3)\end{array}$ & $\begin{array}{l}38.9(38.6- \\
39.2)\end{array}$ & $38.9(38.3-39.1)$ & $\begin{array}{l}39.1(38.5- \\
39.4)\end{array}$ & $\begin{array}{l}38.9(38.3- \\
39.5)\end{array}$ & $\begin{array}{l}38.9(38.6- \\
39.2)\end{array}$ \\
\hline Heart rate (beats/min) & $72(64-80)$ & $76^{1}(68-84)$ & $80^{1,2}(68-101)$ & $\begin{array}{l}108^{1,2,3,5}(96- \\
122)\end{array}$ & $84^{1,2}(76-99)$ & $99^{1,2}(76-116)$ & $76(69-90)$ \\
\hline $\begin{array}{l}\text { Respiratory rate (breaths/ } \\
\text { min) }\end{array}$ & $27(24-32)$ & $28(24-32)$ & $28^{1}(20-36)$ & $29^{1}(24-36)$ & $28(24-40)$ & $32^{1}(24-41)$ & $29(24-38)$ \\
\hline
\end{tabular}

${ }^{1-5}, P<0.05$, Kruskal Wallis test

${ }^{1}$ Different from controls

2 Different from TRP

${ }^{3}$ Different from U1

${ }^{4}$ Different from U2

${ }^{5}$ Different from U3 
Table 2 Frequency distributions of the clinical findings in healthy control cows, cows with traumatic reticuloperitonitis (TRP) and cows with type 1 (U1), type 2 (U2), type 3 (U3), type 4 (U4) or type 5 (U5) abomasal ulcer

\begin{tabular}{|c|c|c|c|c|c|c|c|c|c|}
\hline Variable & Classification & Controls & TRP & U1 & U2 & U3 & U4 & U5 & $\mathrm{Chi}^{2}$ \\
\hline \multirow[t]{12}{*}{ Rectal temperature } & $\begin{array}{l}38.6-39.0^{\circ} \mathrm{C} \text { (normal } \\
\text { range) }\end{array}$ & $\begin{array}{l}103 \\
(57 \%)^{2,4,5,6}\end{array}$ & $160(32 \%)^{1}$ & $41(44 \%)^{6}$ & $56(38 \%)^{1,6}$ & $14(23 \%)^{1}$ & $16(18 \%)^{1,3,4}$ & $5(39 \%)$ & 79 \\
\hline & $\leq 38.5$ or $>39.0^{\circ} \mathrm{C}$ & 79 (43\%) & $343(68 \%)$ & $52(56 \%)$ & 89 (61\%) & $46(77 \%)$ & $71(82 \%)$ & $8(62 \%)$ & \\
\hline & $\leq 38.5^{\circ} \mathrm{C}$ (decreased) & $21(11 \%)^{2,4,6}$ & $126(25 \%)^{1}$ & $21(23 \%)$ & $46(32 \%)^{1}$ & $16(27 \%)$ & $30(35 \%)^{1}$ & $2(15 \%)$ & \\
\hline & $>38.5^{\circ} \mathrm{C}$ & 161 (89\%) & 377 (75\%) & $72(77 \%)$ & 99 (68\%) & $44(73 \%)$ & $57(66 \%)$ & $11(85 \%)$ & 26 \\
\hline & $\leq 38.0^{\circ} \mathrm{C}$ (decreased) & $2(1 \%)^{3,4,6,7}$ & $34(7 \%)^{4,6}$ & $8(9 \%)^{1}$ & $22(15 \%)^{1,2}$ & $4(7 \%)$ & $16(18 \%)^{1,2}$ & $2(15 \%)^{1}$ & \\
\hline & $>38.0^{\circ} \mathrm{C}$ & 180 (99\%) & 469 (93\%) & 85 (91\%) & $123(85 \%)$ & $56(93 \%)$ & $71(82 \%)$ & $11(85 \%)$ & 36 \\
\hline & $>39.0^{\circ} \mathrm{C}$ (increased) & $58(32 \%)$ & $217(43 \%)$ & $31(33 \%)$ & $43(30 \%)$ & $30(50 \%)$ & $41(47 \%)$ & $6(46 \%)$ & \\
\hline & $\leq 39.0^{\circ} \mathrm{C}$ & $124(68 \%)$ & $286(57 \%)$ & $62(67 \%)$ & $102(70 \%)$ & $30(50 \%)$ & $46(53 \%)$ & 7 (54\%) & 20 \\
\hline & $>39.5^{\circ} \mathrm{C}$ (increased) & $11(6 \%)^{6}$ & $71(14 \%)^{4}$ & $9(10 \%)$ & $6(4 \%)^{2,6}$ & $11(18 \%)^{4}$ & $20(23 \%)^{1,4}$ & $0(0 \%)$ & \\
\hline & $\leq 39.5^{\circ} \mathrm{C}$ & 171 (94\%) & $432(86 \%)$ & $84(90 \%)$ & 139 (96\%) & $49(82 \%)$ & $67(77 \%)$ & $13(100 \%)$ & 30 \\
\hline & $>40.0^{\circ} \mathrm{C}$ (increased) & $1(1 \%)$ & $26(5 \%)$ & $3(3 \%)$ & $2(1 \%)$ & $6(10 \%)$ & $3(3 \%)$ & $0(0 \%)$ & \\
\hline & $\leq 40.0^{\circ} \mathrm{C}$ & 181 (99\%) & 477 (95\%) & $90(97 \%)$ & 143 (99\%) & $54(90 \%)$ & 84 (97\%) & $13(100 \%)$ & 14 \\
\hline \multirow[t]{8}{*}{ Heart rate } & $\begin{array}{l}60-80 \text { bmp (normal } \\
\text { range) }\end{array}$ & $\begin{array}{l}139 \\
(76 \%)^{3,4,5,6}\end{array}$ & $\begin{array}{l}349 \\
(70 \%)^{3,4,5,6}\end{array}$ & $\begin{array}{l}45 \\
(48 \%)^{1,2,4}\end{array}$ & $\begin{array}{l}15 \\
(10 \%)^{1,2,3,5,6,7}\end{array}$ & $\begin{array}{l}27 \\
(45 \%)^{1,2,4}\end{array}$ & $26(30 \%)^{1,2,4}$ & $8(57 \%)^{4}$ & \\
\hline & $<60$ or $>80 / \mathrm{min}$ & $43(24 \%)$ & $153(30 \%)$ & 49 (52\%) & $130(90 \%)$ & $33(55 \%)$ & $61(70 \%)$ & $6(43 \%)$ & 220 \\
\hline & $>80 /$ min (increased) & $\begin{array}{l}28 \\
(15 \%)^{3,4,5,6}\end{array}$ & $\begin{array}{l}130 \\
(26 \%)^{3,4,5,6}\end{array}$ & $\begin{array}{l}46 \\
(49 \%)^{1,2,4}\end{array}$ & $\begin{array}{l}130 \\
(90 \%)^{1,2,3,5,6,7}\end{array}$ & $\begin{array}{l}33 \\
(55 \%)^{1,2,4}\end{array}$ & $59(68 \%)^{1,2,4}$ & $5(36 \%)^{4}$ & \\
\hline & $\leq 80 / \min$ & $154(85 \%)$ & $372(74 \%)$ & $48(51 \%)$ & $15(10 \%)$ & $27(45 \%)$ & $28(32 \%)$ & $9(64 \%)$ & 274 \\
\hline & $>100 /$ min (increased) & $2(1 \%)^{3,4,5,6,7}$ & $\begin{array}{l}22 \\
(4 \%)^{3,4,5,6,7}\end{array}$ & $\begin{array}{l}23 \\
(24 \%)^{1,2,4,7}\end{array}$ & $\begin{array}{l}90 \\
(62 \%)^{1,2,3,5,6}\end{array}$ & $\begin{array}{l}10 \\
(17 \%)^{1,2,4,6,7}\end{array}$ & $\begin{array}{l}36 \\
(41 \%)^{1,2,4,5,7}\end{array}$ & $\begin{array}{l}12 \\
(86 \%)^{1,2,3,5,6}\end{array}$ & \\
\hline & $\leq 100 / \mathrm{min}$ & 180 (99\%) & 480 (96\%) & $71(75 \%)$ & $55(38 \%)$ & $50(83 \%)$ & $51(59 \%)$ & $2(14 \%)$ & 368 \\
\hline & $>120 /$ min (increased) & $1(1 \%)^{3,4,6}$ & $7(1 \%)^{3,4,6}$ & $7(7 \%)^{1,2,4}$ & $\begin{array}{l}37 \\
(26 \%)^{1,2,3,5}\end{array}$ & $1(2 \%)^{4}$ & $13(15 \%)^{1,2}$ & $1(7 \%)$ & \\
\hline & $\leq 120 / \mathrm{min}$ & 181 (99\%) & 495 (99\%) & 87 (93\%) & $108(74 \%)$ & $59(98 \%)$ & $74(85 \%)$ & $13(93 \%)$ & 137 \\
\hline \multirow[t]{8}{*}{ Respiratory rate } & $\begin{array}{l}15-35 \text { breaths/min } \\
\text { (normal range) }\end{array}$ & $\begin{array}{l}155 \\
(85 \%)^{4,5,6}\end{array}$ & $380(76 \%)$ & $67(71 \%)$ & $92(64 \%)^{1}$ & $38(63 \%)^{1}$ & $53(62 \%)^{1}$ & $9(64 \%)$ & \\
\hline & $<15$ or $>35 / \mathrm{min}$ & $27(15 \%)$ & $121(24 \%)$ & 27 (29\%) & $52(36 \%)$ & $22(37 \%)$ & $33(38 \%)$ & $5(36 \%)$ & 31 \\
\hline & $>35 /$ min (increased) & $\begin{array}{l}27 \\
(15 \%)^{2,3,4,5,6,7}\end{array}$ & $\begin{array}{l}117 \\
(23 \%)^{1,4,5,6}\end{array}$ & $27(29 \%)^{1}$ & $52(36 \%)^{1,2}$ & $22(37 \%)^{1,2}$ & $33(38 \%)^{1,2}$ & $5(36 \%)^{1}$ & \\
\hline & $\leq 35 / \min$ & 155 (85\%) & $384(77 \%)$ & 67 (71\%) & 92 (64\%) & $38(63 \%)$ & $53(62 \%)$ & $9(64 \%)$ & 33 \\
\hline & $>45 /$ min (increased) & $4(2 \%)^{3,4,5,6,7}$ & $\begin{array}{l}21 \\
(4 \%)^{3,4,5,6,7}\end{array}$ & $\begin{array}{l}13 \\
(14 \%)^{1,2,7}\end{array}$ & $20(14 \%)^{1,2,7}$ & $9(15 \%)^{1,2,7}$ & $17(20 \%)^{1,2,7}$ & $\begin{array}{l}14 \\
(100 \%)^{1,2,3,4,5,6}\end{array}$ & \\
\hline & $\leq 45 / \min$ & 178 (98\%) & 480 (96\%) & $81(86 \%)$ & 124 (86\%) & $51(85 \%)$ & 69 (80\%) & $0(0 \%)$ & 186 \\
\hline & $>55 /$ min (increased) & $1(1 \%)^{3,4,7}$ & $12(2 \%)^{3,4,7}$ & $9(10 \%)^{1,2}$ & $12(8 \%)^{1,2}$ & $4(7 \%)$ & $14(16 \%)^{1,2}$ & 0 & \\
\hline & $\leq 55 / \min$ & 181 (99\%) & 489 (98\%) & $85(90 \%)$ & $132(92 \%)$ & $56(93 \%)$ & 72 (84\%) & 0 & 47 \\
\hline \multirow[t]{2}{*}{ Demeanour } & abnormal & $\begin{array}{l}2 \\
(1 \%)^{2,3,4,5,6,7}\end{array}$ & $\begin{array}{l}438 \\
(87 \%)^{1,4,6}\end{array}$ & $\begin{array}{l}88 \\
(94 \%)^{1,6}\end{array}$ & $141(98 \%)^{1,2}$ & $57(95 \%)^{1,6}$ & $\begin{array}{l}87 \\
(100 \%)^{1,2,3,5,7}\end{array}$ & $13(93 \%)^{1,6}$ & \\
\hline & normal & 180 (99\%) & 65 (13\%) & $6(6 \%)$ & $4(2 \%)$ & $3(5 \%)$ & $0(0 \%)$ & $1(7 \%)$ & 690 \\
\hline
\end{tabular}


Table 2 Frequency distributions of the clinical findings in healthy control cows, cows with traumatic reticuloperitonitis (TRP) and cows with type 1 (U1), type 2 (U2), type 3 (U3), type 4 (U4) or type 5 (U5) abomasal ulcer (Continued)

\begin{tabular}{|c|c|c|c|c|c|c|c|c|c|}
\hline Variable & Classification & Controls & TRP & U1 & U2 & U3 & U4 & U5 & $\mathrm{Chi}^{2}$ \\
\hline \multirow[t]{2}{*}{ Signs of colic } & yes & $0(0 \%)^{3,4,6,7}$ & $16(3 \%)^{3,4,6}$ & $\begin{array}{l}20 \\
(21 \%)^{1,2,5}\end{array}$ & $15(10 \%)^{1.2}$ & $1(2 \%)^{3}$ & $9(10 \%)^{1,2}$ & $2(14 \%)^{1}$ & \\
\hline & no & $182(100 \%)$ & 487 (97\%) & 74 (79\%) & $130(90 \%)$ & 59 (98\%) & 78 (90\%) & $12(86 \%)$ & 71 \\
\hline \multirow[t]{2}{*}{ Arched back } & yes & $\begin{array}{l}1 \\
(0.5 \%)^{2,3,5,6,7}\end{array}$ & $91(18 \%)^{1,4}$ & $11(12 \%)^{1}$ & $5(3 \%)^{2,6,7}$ & $8(13 \%)^{1}$ & $24(28 \%)^{1,4}$ & $5(36 \%)^{1,4}$ & \\
\hline & no & 181 (99\%) & $412(82 \%)$ & $83(88 \%)$ & 140 (97\%) & $52(87 \%)$ & $63(72 \%)$ & $9(64 \%)$ & 69 \\
\hline $\begin{array}{l}\text { Abdominal } \\
\text { guarding }\end{array}$ & $\begin{array}{l}\text { yes } \\
\text { no }\end{array}$ & $\begin{array}{l}36 \\
(20 \%)^{2,3,4,5,6,7,7} \\
146(80 \%)\end{array}$ & $\begin{array}{l}273 \\
(54 \%)^{1,6,7} \\
228(46 \%)\end{array}$ & $\begin{array}{l}53 \\
(59 \%)^{1,6} \\
37(41 \%)\end{array}$ & $\begin{array}{l}61(43 \%)^{1,6,7} \\
81(57 \%)\end{array}$ & $\begin{array}{l}36(61 \%)^{1} \\
23(39 \%)\end{array}$ & $\begin{array}{l}68 \\
(81 \%)^{1,2,3,4} \\
16(19 \%)\end{array}$ & $\begin{array}{l}14(100 \%)^{1,2,4} \\
0(0 \%)\end{array}$ & 125 \\
\hline \multirow[t]{2}{*}{ Bruxism } & yes & $\begin{array}{l}1 \\
(0.5 \%)^{2,3,4,5,6,7}\end{array}$ & $103(21 \%)^{1}$ & $14(15 \%)^{1}$ & $18(12 \%)^{1}$ & $11(18 \%)^{1}$ & $22(25 \%)^{1}$ & $3(21 \%)^{1}$ & \\
\hline & no & $181(99.5 \%)$ & 400 (79\%) & $80(85 \%)$ & 127 (88\%) & 49 (82\%) & $65(75 \%)$ & $11(79 \%)$ & 48 \\
\hline \multirow[t]{2}{*}{ Scleral vessels } & congested & $\begin{array}{l}42 \\
(29 \%)^{2,3,5,6,7}\end{array}$ & $\begin{array}{l}393 \\
(79 \%)^{1,4}\end{array}$ & $\begin{array}{l}83 \\
(89 \%)^{1,4}\end{array}$ & $\begin{array}{l}51 \\
(35 \%)^{2,3,5,6,7}\end{array}$ & $43(73 \%)^{1,4}$ & $66(77 \%)^{1,4}$ & $11(79 \%)^{1,4}$ & \\
\hline & not congested & $104(71 \%)$ & 107 (21\%) & $10(11 \%)$ & $94(65 \%)$ & $16(27 \%)$ & $20(23 \%)$ & $3(21 \%)$ & 216 \\
\hline \multirow[t]{2}{*}{$\begin{array}{l}\text { Mucous } \\
\text { membranes }\end{array}$} & pale & $5(3 \%)^{4,6}$ & $37(7 \%)^{4,6}$ & $9(10 \%)^{4}$ & $\begin{array}{l}100 \\
(69 \%)^{1,2,3,5,6,6,7}\end{array}$ & $2(3 \%)^{4,6}$ & $\begin{array}{l}23 \\
(27 \%)^{1,2,4,5}\end{array}$ & $2(14 \%)^{4}$ & \\
\hline & not pale & 177 (97\%) & 458 (93\%) & 83 (90\%) & 45 (31\%) & 58 (97\%) & $62(73 \%)$ & $12(86 \%)$ & 360 \\
\hline \multirow[t]{4}{*}{ Rumen motility } & reduced or absent & $\begin{array}{l}24 \\
(13 \%)^{2,3,4,5,6,7}\end{array}$ & $\begin{array}{l}354 \\
(73 \%)^{1,4,5,6}\end{array}$ & $54(90 \%)^{1}$ & $131(92 \%)^{1,2}$ & $53(93 \%)^{1,2}$ & $85(93 \%)^{1,2}$ & $13(93 \%)^{1}$ & \\
\hline & normal & 158 (87\%) & $133(27 \%)$ & $6(10 \%)$ & $12(8 \%)$ & $4(7 \%)$ & $1(7 \%)$ & $1(7 \%)$ & 372 \\
\hline & absent (rumen atony) & $\begin{array}{l}0 \\
(0 \%)^{2,3,4,5,6,7}\end{array}$ & $\begin{array}{l}29 \\
(6 \%)^{1,3,4,5,6,7}\end{array}$ & $\begin{array}{l}50 \\
(56 \%)^{1,2,6}\end{array}$ & $64(45 \%)^{1,2}$ & $28(49 \%)^{1,2}$ & $23(27 \%)^{1,2,3}$ & $5(36 \%)^{1,2}$ & \\
\hline & reduced or normal & $182(100 \%)$ & $458(94 \%)$ & $40(44 \%)$ & $79(55 \%)$ & $29(51 \%)$ & $63(73 \%)$ & $9(64 \%)$ & 278 \\
\hline \multirow[t]{2}{*}{ Foreign body tests } & at least one test positive & $81(44 \%)^{2,3}$ & $\begin{array}{l}296 \\
(60 \%)^{1,3,4}\end{array}$ & $\begin{array}{l}19 \\
(24 \%)^{1,2,6}\end{array}$ & $36(28 \%)^{2,6}$ & $26(45 \%)$ & $44(58 \%)^{3,4}$ & $5(39 \%)$ & \\
\hline & $\begin{array}{l}\text { all foreign body tests } \\
\text { negative }\end{array}$ & $101(56 \%)$ & $199(40 \%)$ & $61(76 \%)$ & 91 (72\%) & $32(55 \%)$ & $32(42 \%)$ & $8(61 \%)$ & 70 \\
\hline \multirow[t]{2}{*}{$\begin{array}{l}\text { PSA/BSA on the } \\
\text { right side }\end{array}$} & PSA and/or BSA positive & $\begin{array}{l}19 \\
(10 \%)^{3,4,5,6,7}\end{array}$ & $\begin{array}{l}87 \\
(17 \%)^{3,4,5,6,7}\end{array}$ & $\begin{array}{l}50 \\
(53 \%)^{1,2,4}\end{array}$ & $47(33 \%)^{1,2,3}$ & $28(47 \%)^{1,2}$ & $44(51 \%)^{1,2}$ & $9(64 \%)^{1,2}$ & \\
\hline & PSA and BSA negative & $163(90 \%)$ & $416(83 \%)$ & $44(47 \%)$ & $96(67 \%)$ & 32 (53\%) & $43(49 \%)$ & $5(36 \%)$ & 133 \\
\hline \multirow[t]{2}{*}{ Faecal colour } & dark or black & $0(0 \%)^{3,4,5,6,7}$ & $\begin{array}{l}0 \\
(0 \%)^{3,4,5,6,7}\end{array}$ & $\begin{array}{l}14 \\
(18 \%)^{1,2,4}\end{array}$ & $\begin{array}{l}115 \\
(80 \%)^{1,2,3,5,6,7}\end{array}$ & $6(11 \%)^{1,2,4}$ & $12(16 \%)^{1,2,4}$ & $3(21 \%)^{1,2,4}$ & \\
\hline & normal & $182(100 \%)$ & 486 (100\%) & 64 (82\%) & 28 (20\%) & 47 (89\%) & 63 (84\%) & 11 (79\%) & 615 \\
\hline
\end{tabular}

PSA Percussion and simultaneous auscultation, BSA Ballottement and simultaneous auscultation, NR Not recorded, NA Not applicable

${ }^{1}$ Different from controls, $P<0.01$

${ }^{2}$ Different from TRP, $P<0.01$

${ }^{3}$ Different from U1, $P<0.01$

${ }^{4}$ Different from U2, $P<0.01$

${ }^{5}$ Different from U3, $P<0.01$

${ }^{6}$ Different from U4, $P<0.01$

${ }^{7}$ Different from U5 $P<0.01$ 


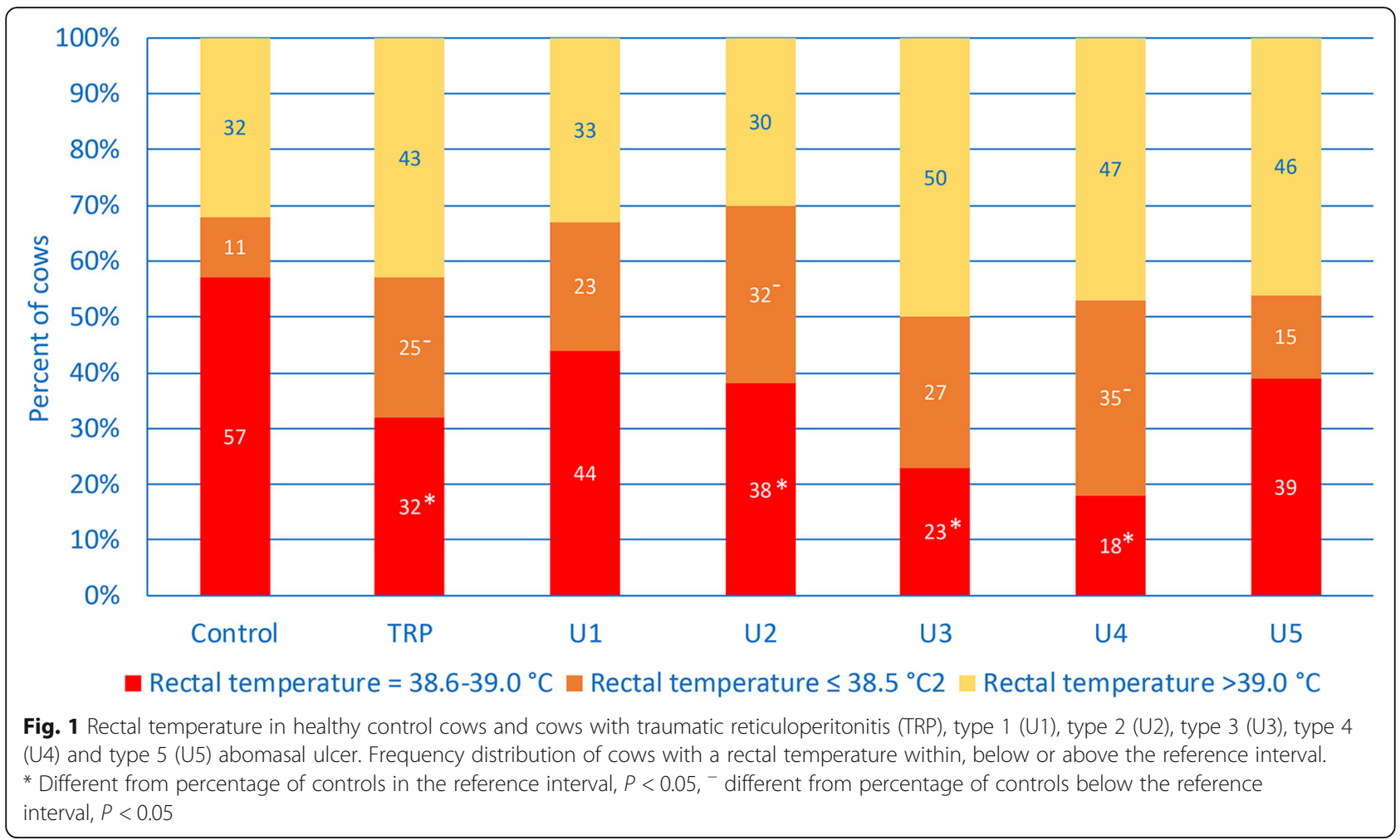

in ill cows ranged from 79 to 91 , and the positive predictive value from 87 to $100 \%$ (Table 3).

\section{Colic}

Signs of colic such as restlessness, shifting weight, kicking and a sunken back did not occur in control cows (Table 2) but were seen in cows with U1 (21\%), U2 (10\%), U4 (10\%) and U5 (14\%). The LR $\mathrm{L}_{+}$for signs of colic in cows with U1, U2, U4 and U5 were 21, 10, 10 and 14 , respectively, and the positive predictive value was $100 \%$ in all ill cows (Table 3 ).

\section{Arched back}

An arched back was seen in $0.5 \%$ of the control cows (Table 2) and with the exception of cows with U2, was significantly more frequent in the ill cows (TRP 18\%, U1 $12 \%$, U3 13\%, U4 28\%, U5 36\%). The frequency of arched back was significantly lower in cows with TRP than in cows with U4 and U5. The LR for arched back exceeded 10 in cows with TRP (18), U1 (12), U3 (13), U4 (28) and U5 (36), and the positive predictive value was $100 \%$ in all ill cows (Table 3 ).

\section{Abdominal guarding}

Abdominal guarding occurred in $20 \%$ of controls (Table 2) and was significantly more frequent in ill cows (TRP 54\%, U1 59\%, U2 43\%, U3 61\%, U4 81\%, U5 100\%). The $\mathrm{LR}_{+}$was small with values between 2 and 5 (Table 3 ).

\section{Bruxism}

Bruxism occurred in $0.5 \%$ of controls (Table 2) and was significantly more frequent in ill cows (TRP 21\%, U1 $15 \%$, U2 12\%, U3 18\%, U4 25\%, U5 21\%). The $\mathrm{LR}_{+}$ exceeded 10 in all ill cows (TRP 20, U1 15, U2 12, U3 18 , U4 25, U5 21) and the positive predictive value was $100 \%$ (Table 3).

\section{Scleral congestion}

Scleral congestion occurred in $29 \%$ of the controls (Table 2) and significantly more frequently in 73 to $89 \%$ of the ill cows with the exception of the cows with U2. The positive predictive value for TRP was 90\% (Table 3).

\section{Mucous membrane colour}

Pale mucous membranes occurred in 3\% of control cows (Table 2) and significantly more frequently in cows with U2 (69\%) and U4 (27\%). The LR for pale mucous membranes was 25 for cows with U2 and 10 for cows with U4, and the predictive value was $95 \%$ in cows with U2 (Table 3).

\section{Rumen motility}

Reduced rumen motility occurred in 13\% of controls (Table 2 and Fig. 4) and significantly more often in all groups of ill cows. Rumen atony did not occur in controls, and it was significantly less frequent in cows with TRP (6\%) than in the other ill cows (U1 56\%, U2 45\%, U3 49\%, U4 27\%, U5 36\%). The $\mathrm{LR}_{+}$for rumen atony 
Table 3 Diagnostic sensitivity and specificity, positive and negative predictive values and positive likelihood ratio of clinical findings in cows with traumatic reticuloperitonitis (TRP) and cows with type 1 (U1), type 2 (U2), type 3 (U3), type 4 (U4) or type 5 (U5) abomasal ulcer (in percent)

\begin{tabular}{|c|c|c|c|c|c|c|c|}
\hline Variable & Reliability indices & TRP & U1 & U2 & U3 & U4 & U5 \\
\hline \multirow[t]{5}{*}{ Rectal temperature $\leq 38.5^{\circ} \mathrm{C}$} & Diagn. sensitivity & 25 & 29 & 31 & 27 & 34 & 15 \\
\hline & Diagn. specificity & 88 & 88 & 88 & 88 & 88 & 88 \\
\hline & Pos. pred. Value & 86 & 50 & 68 & 43 & 59 & 9 \\
\hline & Neg. pred. Value & 30 & 69 & 62 & 79 & 74 & 94 \\
\hline & $\mathrm{LR}_{+}$ & 2 & 2 & 3 & 2 & 3 & 1 \\
\hline \multirow[t]{5}{*}{ Rectal temperature $\leq 38.0^{\circ} \mathrm{C}$} & Diagn. sensitivity & 7 & 9 & 15 & 7 & 18 & 15 \\
\hline & Diagn. specificity & 99 & 99 & 99 & 99 & 99 & 99 \\
\hline & Pos. pred. Value & 94 & 80 & 92 & 67 & 89 & 50 \\
\hline & Neg. pred. Value & 28 & 68 & 59 & 76 & 72 & 94 \\
\hline & $\mathrm{LR}_{+}$ & 6 & 8 & 14 & 6 & 17 & 14 \\
\hline \multirow[t]{5}{*}{ Rectal temperature $>39.0^{\circ} \mathrm{C}$} & Diagn. sensitivity & 43 & 33 & 30 & 50 & 47 & 50 \\
\hline & Diagn. specificity & 68 & 68 & 68 & 68 & 68 & 68 \\
\hline & Pos. pred. Value & 79 & 35 & 43 & 34 & 41 & 9 \\
\hline & Neg. pred. Value & 30 & 67 & 55 & 81 & 73 & 95 \\
\hline & $\mathrm{LR}_{+}$ & 1 & 1 & 1 & 2 & 1 & 2 \\
\hline \multirow[t]{5}{*}{ Rectal temperature $>39.5^{\circ} \mathrm{C}$} & Diagn. sensitivity & 14 & 10 & 4 & 18 & 23 & NA \\
\hline & Diagn. specificity & 94 & 94 & 94 & 94 & 94 & 94 \\
\hline & Pos. pred. Value & 87 & 45 & 35 & 50 & 65 & NA \\
\hline & Neg. pred. Value & 28 & 67 & 55 & 78 & 72 & 93 \\
\hline & $L R_{+}$ & 2 & 1 & 1 & 3 & 4 & NA \\
\hline \multirow[t]{5}{*}{ Rectal temperature $>40.0^{\circ} \mathrm{C}$} & Diagn. sensitivity & 5 & 3 & 1 & 10 & 3 & NA \\
\hline & Diagn. specificity & 99 & 99 & 99 & 99 & 99 & 99 \\
\hline & Pos. pred. Value & 96 & 75 & 67 & 86 & 75 & NA \\
\hline & Neg. pred. Value & 28 & 67 & 56 & 77 & 68 & 93 \\
\hline & $L R_{+}$ & 9 & 6 & 3 & 18 & 6 & NA \\
\hline \multirow[t]{5}{*}{ Heart rate $>80 \mathrm{bpm}$} & Diagn. sensitivity & 26 & 49 & 90 & 55 & 68 & 36 \\
\hline & Diagn. specificity & 85 & 85 & 85 & 85 & 85 & 85 \\
\hline & Pos. pred. Value & 82 & 62 & 82 & 54 & 68 & 15 \\
\hline & Neg. pred. Value & 29 & 76 & 91 & 85 & 85 & 94 \\
\hline & $\mathrm{LR}_{+}$ & 2 & 3 & 6 & 4 & 4 & 2 \\
\hline \multirow[t]{5}{*}{ Heart rate $>100 \mathrm{bpm}$} & Diagn. sensitivity & 4 & 24 & 62 & 17 & 41 & 86 \\
\hline & Diagn. specificity & 99 & 99 & 99 & 99 & 99 & 99 \\
\hline & Pos. pred. Value & 92 & 92 & 98 & 83 & 95 & 86 \\
\hline & Neg. pred. Value & 27 & 72 & 77 & 78 & 78 & 99 \\
\hline & $\mathrm{LR}_{+}$ & 4 & 22 & 56 & 15 & 38 & 78 \\
\hline \multirow[t]{5}{*}{ Heart rate $>120 \mathrm{bpm}$} & Diagn. sensitivity & 1 & 7 & 26 & 2 & 15 & 7 \\
\hline & Diagn. specificity & 99 & 99 & 99 & 99 & 99 & 99 \\
\hline & Pos. pred. Value & 88 & 88 & 97 & 50 & 93 & 50 \\
\hline & Neg. pred. Value & 27 & 68 & 63 & 75 & 71 & 93 \\
\hline & $\mathrm{LR}_{+}$ & 3 & 14 & 46 & 3 & 27 & 13 \\
\hline \multirow[t]{2}{*}{ Respiratory rate $>35$ breaths/min } & Diagn. sensitivity & 23 & 29 & 36 & 37 & 38 & 36 \\
\hline & Diagn. specificity & 85 & 85 & 85 & 85 & 85 & 85 \\
\hline
\end{tabular}


Table 3 Diagnostic sensitivity and specificity, positive and negative predictive values and positive likelihood ratio of clinical findings in cows with traumatic reticuloperitonitis (TRP) and cows with type 1 (U1), type 2 (U2), type 3 (U3), type 4 (U4) or type 5 (U5) abomasal ulcer (in percent) (Continued)

\begin{tabular}{|c|c|c|c|c|c|c|c|}
\hline Variable & Reliability indices & TRP & U1 & U2 & U3 & U4 & U5 \\
\hline & Pos. pred. Value & 81 & 50 & 66 & 45 & 55 & 16 \\
\hline & Neg. pred. Value & 29 & 70 & 63 & 80 & 75 & 95 \\
\hline & $\mathrm{LR}_{+}$ & 2 & 2 & 2 & 2 & 3 & 2 \\
\hline \multirow[t]{5}{*}{ Respiratory rate $>45$ breaths $/ \mathrm{min}$} & Diagn. sensitivity & 4 & 14 & 14 & 15 & 20 & NA \\
\hline & Diagn. specificity & 98 & 98 & 98 & 98 & 98 & 98 \\
\hline & Pos. pred. Value & 84 & 76 & 83 & 69 & 81 & NA \\
\hline & Neg. pred. Value & 27 & 69 & 59 & 78 & 72 & 93 \\
\hline & $L R_{+}$ & 2 & 6 & 6 & 7 & 9 & NA \\
\hline \multirow[t]{5}{*}{ Respiratory rate $>55$ breaths/min } & Diagn. sensitivity & 2 & 10 & 8 & 7 & 16 & NA \\
\hline & Diagn. specificity & 99 & 99 & 99 & 99 & 99 & 99 \\
\hline & Pos. pred. Value & 92 & 90 & 92 & 80 & 93 & NA \\
\hline & Neg. pred. Value & 27 & 68 & 58 & 76 & 72 & 93 \\
\hline & $\mathrm{LR}_{+}$ & 4 & 17 & 15 & 12 & 30 & NA \\
\hline \multirow[t]{5}{*}{ Abnormal demeanour } & Diagn. sensitivity & 87 & 94 & 97 & 95 & NA & 93 \\
\hline & Diagn. specificity & 99 & 99 & 99 & 99 & 99 & 99 \\
\hline & Pos. pred. Value & 100 & 98 & 99 & 97 & 98 & 87 \\
\hline & Neg. pred. Value & 73 & 97 & 98 & 98 & 100 & 99 \\
\hline & $L R_{+}$ & 79 & 85 & 88 & 86 & 91 & 85 \\
\hline \multirow[t]{5}{*}{ Colic } & Diagn. sensitivity & 3 & 21 & 10 & 2 & 10 & 14 \\
\hline & Diagn. specificity & 100 & 100 & 100 & 100 & 100 & 100 \\
\hline & Pos. pred. Value & 100 & 100 & 100 & 100 & 100 & 100 \\
\hline & Neg. pred. Value & 27 & 71 & 58 & 76 & 70 & 94 \\
\hline & $L R_{+}$ & $3^{1}$ & $21^{1}$ & $10^{1}$ & $2^{1}$ & $10^{1}$ & $14^{1}$ \\
\hline \multirow[t]{5}{*}{ Arched back } & Diagn. sensitivity & 18 & 12 & 3 & 13 & 28 & 36 \\
\hline & Diagn. specificity & 100 & 100 & 100 & 100 & 100 & 100 \\
\hline & Pos. pred. Value & 100 & 100 & 100 & 100 & 100 & 100 \\
\hline & Neg. pred. Value & 31 & 69 & 57 & 78 & 74 & 95 \\
\hline & $\mathrm{LR}_{+}$ & $18^{1}$ & $12^{1}$ & 3 & $13^{1}$ & $28^{1}$ & $36^{1}$ \\
\hline \multirow[t]{5}{*}{ Abdominal guarding } & Diagn. sensitivity & 54 & 59 & 43 & 61 & 81 & 100 \\
\hline & Diagn. specificity & 80 & 80 & 80 & 80 & 80 & 80 \\
\hline & Pos. pred. Value & 88 & 60 & 63 & 50 & 65 & 28 \\
\hline & Neg. pred. Value & 39 & 80 & 64 & 86 & 90 & 100 \\
\hline & $L R_{+}$ & 3 & 3 & 2 & 3 & 4 & 5 \\
\hline \multirow[t]{5}{*}{ Bruxism } & Diagn. sensitivity & 20 & 15 & 12 & 18 & 25 & 21 \\
\hline & Diagn. specificity & 100 & 100 & 100 & 100 & 100 & 100 \\
\hline & Pos. pred. Value & 100 & 100 & 100 & 100 & 100 & 100 \\
\hline & Neg. pred. Value & 31 & 69 & 59 & 79 & 74 & 94 \\
\hline & $\mathrm{LR}_{+}$ & $20^{1}$ & $15^{1}$ & $12^{1}$ & $18^{1}$ & $25^{1}$ & $21^{1}$ \\
\hline \multirow[t]{4}{*}{ Congested scleral vessels } & Diagn. sensitivity & 79 & 89 & 35 & 73 & 77 & 79 \\
\hline & Diagn. specificity & 71 & 71 & 71 & 71 & 71 & 71 \\
\hline & Pos. pred. Value & 90 & 66 & 55 & 51 & 61 & 21 \\
\hline & Neg. pred. Value & 49 & 91 & 53 & 87 & 84 & 97 \\
\hline
\end{tabular}


Table 3 Diagnostic sensitivity and specificity, positive and negative predictive values and positive likelihood ratio of clinical findings in cows with traumatic reticuloperitonitis (TRP) and cows with type 1 (U1), type 2 (U2), type 3 (U3), type 4 (U4) or type 5 (U5) abomasal ulcer (in percent) (Continued)

\begin{tabular}{|c|c|c|c|c|c|c|c|}
\hline Variable & Reliability indices & TRP & U1 & U2 & U3 & U4 & U5 \\
\hline & $\mathrm{LR}_{+}$ & 3 & 3 & 1 & 3 & 3 & 3 \\
\hline \multirow[t]{5}{*}{ Pale mucous membranes } & Diagn. sensitivity & 7 & 10 & 69 & 3 & 27 & 14 \\
\hline & Diagn. specificity & 97 & 97 & 97 & 97 & 97 & 97 \\
\hline & Pos. pred. Value & 88 & 64 & 95 & 29 & 82 & 29 \\
\hline & Neg. pred. Value & 28 & 68 & 80 & 75 & 74 & 94 \\
\hline & $L R_{+}$ & 3 & 4 & 25 & 1 & 10 & 5 \\
\hline \multirow[t]{5}{*}{ Rumen motility reduced or rumen atony } & Diagn. sensitivity & 73 & 90 & 92 & 93 & 99 & 93 \\
\hline & Diagn. specificity & 87 & 87 & 87 & 87 & 87 & 87 \\
\hline & Pos. pred. Value & 94 & 69 & 85 & 69 & 78 & 35 \\
\hline & Neg. pred. Value & 54 & 96 & 93 & 98 & 99 & 99 \\
\hline & $L R_{+}$ & 6 & 7 & 7 & 7 & 8 & 7 \\
\hline \multirow[t]{5}{*}{ Rumen atony } & Diagn. sensitivity & 6 & 56 & 45 & 49 & 27 & 36 \\
\hline & Diagn. specificity & 100 & 100 & 100 & 100 & 100 & 100 \\
\hline & Pos. pred. Value & 100 & 100 & 100 & 100 & 100 & 100 \\
\hline & Neg. pred. Value & 28 & 82 & 70 & 86 & 74 & 95 \\
\hline & $\mathrm{LR}_{+}$ & 6 & $56^{1}$ & $45^{1}$ & $49^{1}$ & $27^{1}$ & $36^{1}$ \\
\hline \multirow[t]{5}{*}{ At least one foreign body test positive } & Diagn. sensitivity & 60 & 21 & 28 & 45 & 58 & 38 \\
\hline & Diagn. specificity & 55 & 55 & 55 & 55 & 55 & 55 \\
\hline & Pos. pred. Value & 79 & 19 & 31 & 24 & 35 & 6 \\
\hline & Neg. pred. Value & 34 & 62 & 53 & 76 & 76 & 93 \\
\hline & $L R_{+}$ & 1 & 1 & 1 & 1 & 1 & 1 \\
\hline \multirow[t]{5}{*}{ PSA and/or BSA on the right side positive } & Diagn. sensitivity & 17 & 53 & 33 & 47 & 51 & 64 \\
\hline & Diagn. specificity & 90 & 90 & 90 & 90 & 90 & 90 \\
\hline & Pos. pred. Value & 82 & 72 & 71 & 60 & 70 & 32 \\
\hline & Neg. pred. Value & 28 & 79 & 63 & 84 & 79 & 97 \\
\hline & $L R_{+}$ & 2 & 5 & 3 & 5 & 5 & 6 \\
\hline \multirow[t]{5}{*}{ Faeces dark or black } & Diagn. sensitivity & NA & 18 & 80 & 11 & 16 & 21 \\
\hline & Diagn. specificity & 100 & 100 & 100 & 100 & 100 & 100 \\
\hline & Pos. pred. Value & NA & 100 & 100 & 100 & 100 & 100 \\
\hline & Neg. pred. Value & 27 & 74 & 87 & 79 & 74 & 94 \\
\hline & $L R_{+}$ & NA & $18^{1}$ & $80^{1}$ & $11^{1}$ & $16^{1}$ & $32^{1}$ \\
\hline
\end{tabular}

${ }^{1}$ The calculation of the $\mathrm{LR}_{+}$required the reduction of the diagnostic specificity from 100 to $99 \%$

PSA Percussion and simultaneous auscultation, BSA Ballottement and simultaneous auscultation, NA not applicable Values between 80 and $89 \%$ are in italic

Values between 90 and $100 \%$ are in bold

Values of $\mathrm{LR}_{+} \geq 10$ are in bold-italic

ranged from 27 to 56 for cows with abomasal ulcer and was 6 for cows with TRP (Table 3). The positive predictive value was $100 \%$ in ill cows.

\section{Foreign body tests}

At least one foreign body test was positive in $44 \%$ of controls (Table 2). This percentage was significantly higher in cows with TRP (60\%) and significantly lower in cows with U1 (24\%), whereas the other groups did not differ from the controls (U2 28\%, U3 45\%, U4 58\%, U5 39\%).

\section{Percussion and auscultation and ballottement and auscultation on the right side}

This procedure produced a positive result in $10 \%$ of the controls and significantly more frequently in cows with abomasal ulcer (U1 53\%, U2 33\%, U3 47\%, U4 51\%, U5 


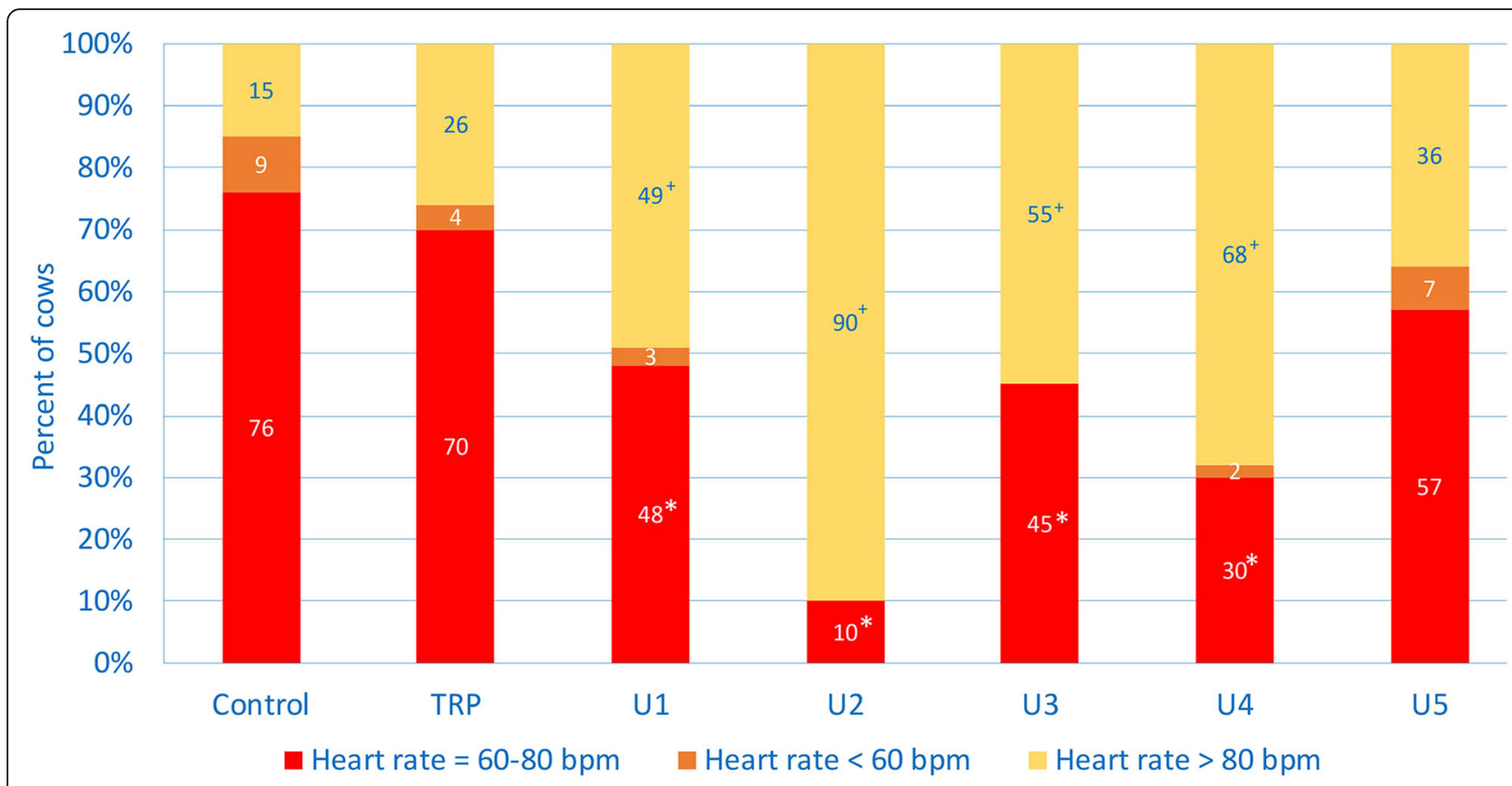

Fig. 2 Heart rate in healthy control cows and cows with traumatic reticuloperitonitis (TRP) and type 1 (U1), type 2 (U2), type 3 (U3), type 4 (U4) and type 5 (U5) abomasal ulcer. Frequency distribution of cows with a heart rate within, below or above the reference interval. * Different from percentage of controls in the reference interval, $P<0.05,{ }^{+}$Different from percentage of controls above the reference interval, $P<0.05$

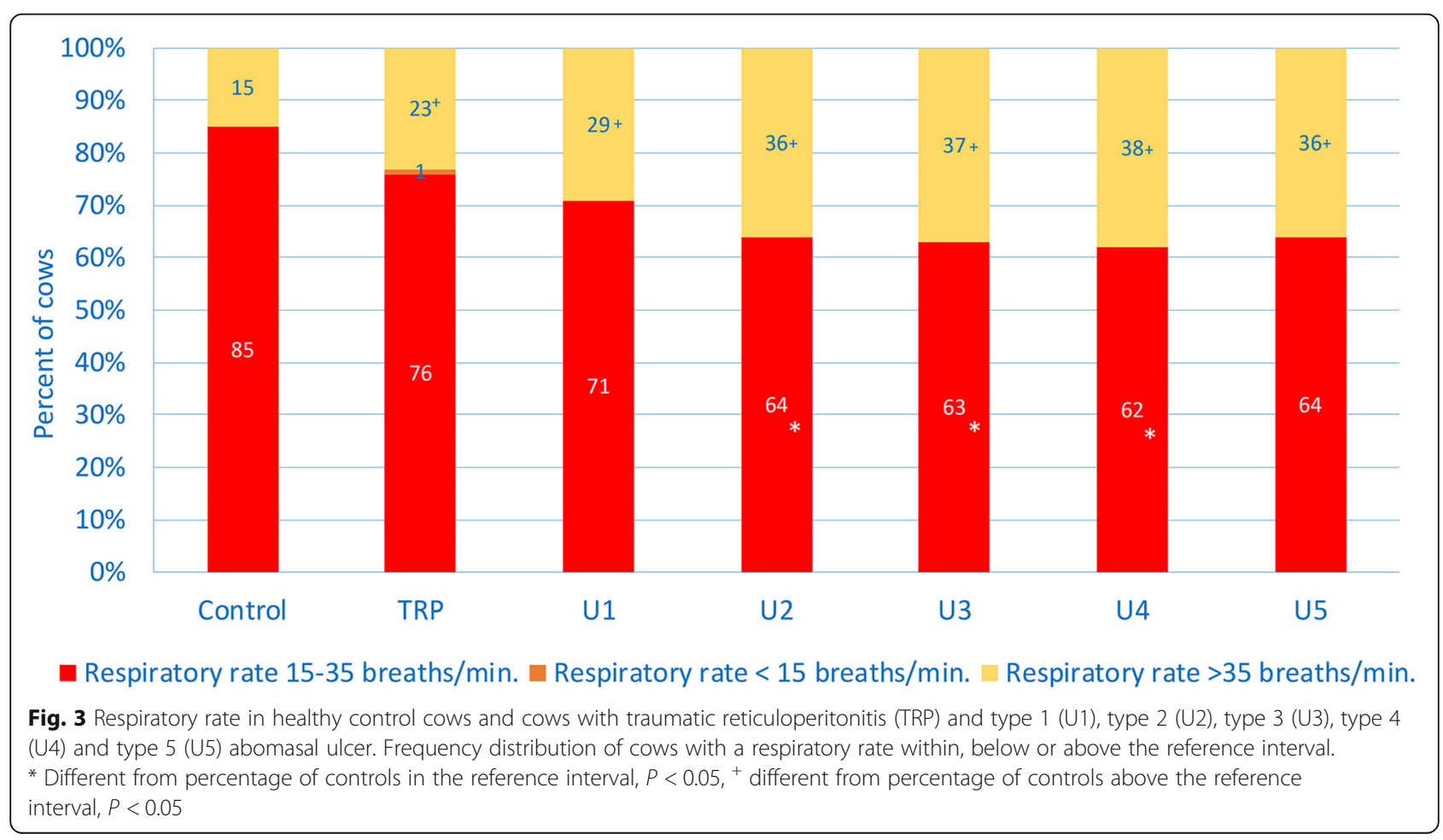




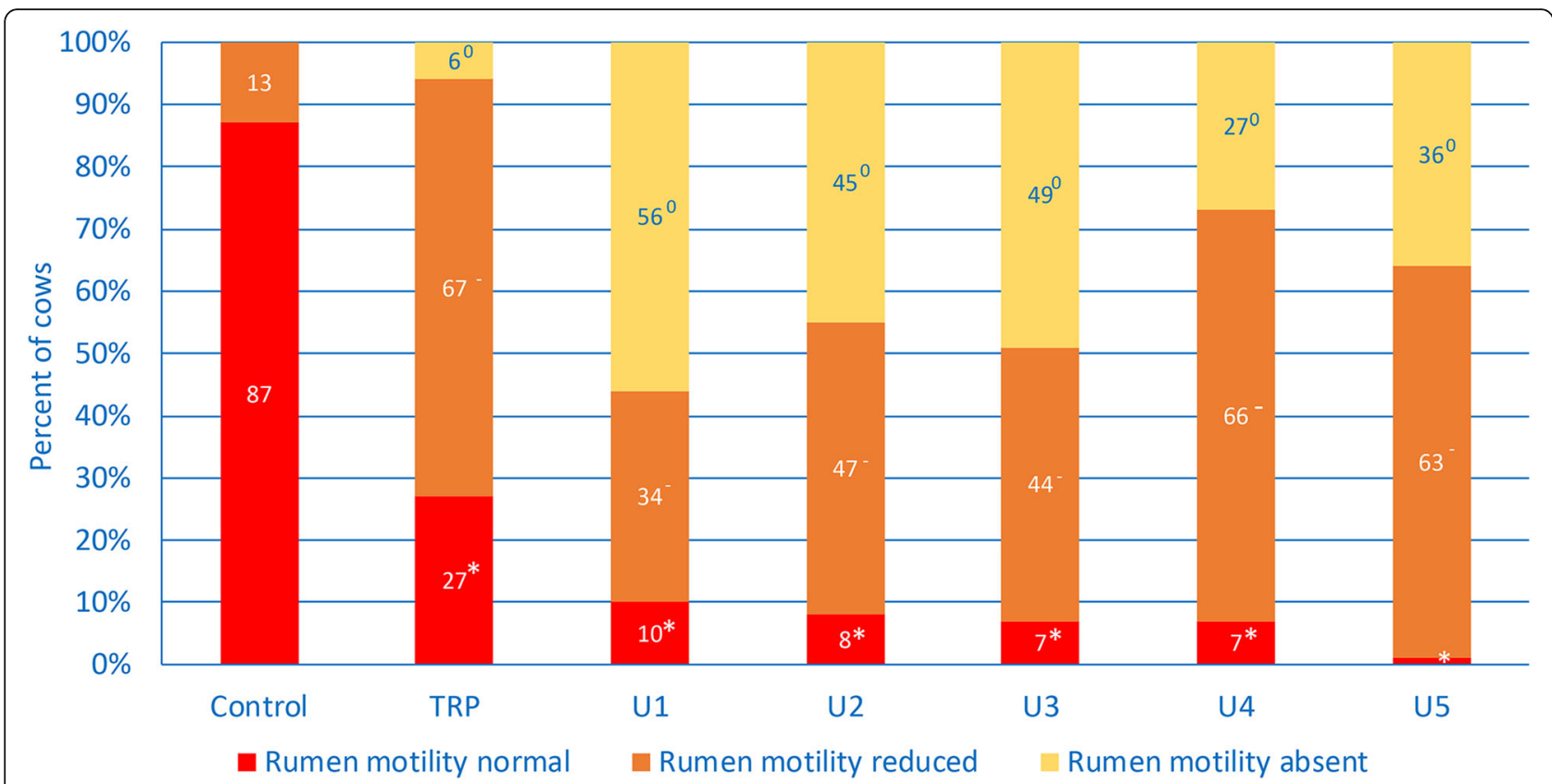

Fig. 4 Rumen motility in healthy control cows and cows with traumatic reticuloperitonitis (TRP), type 1 (U1), type 2 (U2), type 3 (U3), type 4 (U4) and type 5 (U5) abomasal ulcer. Frequency distribution of cows with normal, reduced and absent rumen motility. ${ }^{*}$ Different from percentage of controls with normal rumen motility, $P<0.05$, - different from percentage of controls with reduced rumen motility

64\%; Table 2). The $\mathrm{LR}_{+}$was lower than 10 in all disease groups (Table 3).

\section{Faecal colour}

Dark to black faeces were not seen in controls (Table 2) and in cows with TRP but occurred in cows with abomasal ulcers; it was significantly more frequent in cows with U2 (80\%) than in cows with other ulcer types (11 to $21 \%)$. The $\mathrm{LR}_{+}$for dark to black faeces was greater than 10 in cows with abomasal ulcer (U1 18, U2 80, U3 $11, \mathrm{U} 416$, U5 32), and the positive predictive value was 100\% (Table 3).

\section{Discussion}

The reliability indices shown in Table 3 are typically used as measures of laboratory test performance and only rarely for the characterisation of clinical diagnostic procedures. There is only one study that reported the predictive values for abdominal pain in 26 cows with abomasal ulcer [19]. In that study, the diagnostic sensitivity of abdominal pain was $54 \%$ and the positive predictive value was $48 \%$. When abdominal pain was combined with the variables haematocrit $<24 \%$ and occurrence of occult blood in the faeces, the positive predictive value increased to $100 \%$; however, this was accompanied by a low diagnostic sensitivity of $15 \%$. The present study compared clinical findings of healthy cows and cows with TRP, U1, U2, U3, U4 and U5. To our surprise, even healthy cows had numerous clinical variables with values outside of the reference intervals, but there were also variables that were always or almost always (99.0-99.5\%) within the reference interval and thus well suited for distinguishing healthy cows from ill cows. The variables colic, rumen atony and black faeces provided the best selectivity because these clinical signs never occurred in healthy cows; thus cows with these clinical signs are always ill. Other findings that rarely occurred in healthy cows and therefore indicated illness were arched back and bruxism (each $0.5 \%, 1$ of 182 cows) and abnormal demeanour, rectal temperature $\leq 38.0$ or $>40.0^{\circ} \mathrm{C}$, heart rate $>100 \mathrm{bmp}$ and respiratory rate $>$ 55 breaths per minute (each 1\%, 2 of 182 cows). Only mildly abnormal vital signs such as mild hypothermia $\left(38.1-38.5^{\circ} \mathrm{C}\right)$ or hyperthermia $\left(39.1-39.5^{\circ} \mathrm{C}\right)$, slightly increased heart (81-100 bpm) and respiratory rates (36-45 breaths per $\mathrm{min}$ ) were not suitable as diagnostic criteria because they also occurred in healthy cows. It was surprising that some control cows had abnormal findings. One particular cow had several abnormal signs consecutively but never at the same time. All controls were deemed healthy based on the results as a whole. The fact that some control cows had one abnormal finding emphasizes that differentiation of health and illness cannot usually be based on individual clinical findings but should rather take into account the history and results of all tests. There are numerous physiological causes for these mild deviations including excitement, stress, activity, pregnancy, increased ambient temperature and others [20-22]. Auscultation of reduced rumen motility can be attributable to decreased 
ingestion of fibre, which is needed to generate sound when it rubs against the rumen mucosa [23]; less fibre leads to diminished sound. Other clinical variables seen in control cows and therefore considered to have poor selectivity included positive percussion and/or ballottement and auscultation (10\%), reduced rumen motility (13\%), rectal temperature between 39.0 and $39.5^{\circ} \mathrm{C}(25 \%)$, congested scleral vessels (29\%) and at least one positive foreign body test (44\%). Thus, these findings were not reliable for the differentiation of healthy and ill cows because they commonly occurred in healthy cows. Surprisingly, $44 \%$ of the control cows had at least one positive foreign body test even though TRP and other disorders of the cranial abdomen were not present. This calls into question the diagnostic usefulness of foreign body tests.

The demeanour was well suited for the differentiation of healthy and ill cows, and this was supported by $\mathrm{LRs}_{+}$between 79 and 91 in all groups of ill cows. $\mathrm{A} \mathrm{LR}_{+}>10$ is considered high and indicates that the test can be used to rule in the condition in question [18]. The $\mathrm{LR}_{+}$of a test describes how much more likely it is that the test result (or the clinical finding) is from an ill patient than from a healthy patient [18]. Even though demeanour was good for differentiation of healthy and ill cows, it was not useful for differentiation of the various disease conditions because of the high sensitivity at 87 to $97 \%$, which means that a randomly selected ill cow is highly likely to have an abnormal demeanour.

A rectal temperature in the reference interval had little selectivity, whereas a temperature $\leq 38.0^{\circ} \mathrm{C}$ was significantly more common in cows with $\mathrm{U} 2$ and $\mathrm{U} 4$ than in cows with TRP. The low rectal temperature was thought to be associated with shock in cows with U2 and U4. A rectal temperature $>39.5^{\circ} \mathrm{C}$ was significantly more common in cows with TRP, U3 and U5 than in cows with $\mathrm{U} 2$, but this finding had a relatively low diagnostic sensitivity in all disease groups and was also uncommon in cows with TRP, U3 and U5.

A heart rate $>100 \mathrm{bpm}$ was reliable for differentiation of healthy and ill cows but was only partly useful for differentiation of various disease groups. The diagnostic sensitivity in cows with TRP was only $4 \%$ and therefore these cows were unlikely to have a heart rate exceeding $100 \mathrm{bpm}$. A heart rate $>100 \mathrm{bpm}$ was significantly more frequent in cows with ulcers than in cows with TRP. A heart rate $>100 \mathrm{bpm}$ had a relatively high diagnostic sensitivity only in cows with U2 (62\%) and U5 (86\%).

Signs of colic were well suited for the differentiation of healthy and ill cows because they did not occur in the former and each had a diagnostic specificity and a positive predictive value of $100 \%$. However, the diagnostic sensitivity of signs of colic in the groups of ill cows was low and ranged from 2 to 21\%. This was similar for the variables arched back and bruxism. All these findings (with the exception of arched back in cows with U2) had a high $\mathrm{LR}_{+}$and a low diagnostic sensitivity.

The diagnostic sensitivity of abdominal guarding in 14 cows with U5 was $100 \%$ and thus, based on this study, U5 can be ruled out in the absence of a tense abdominal wall. Otherwise, this clinical sign was unsuitable for the differentiation of healthy and ill cows $\left(\mathrm{LR}_{+} 2\right.$ bis 5$)$ and cows of the different disease groups.

Congestion of scleral vessels had a high diagnostic sensitivity of 73 to $89 \%$ for all ill cows except those with $\mathrm{U} 2$, but the $\mathrm{LR}_{+}$was low at 1 to 3 . Therefore, this clinical sign is not suitable for differentiation of healthy and ill cows or for distinguishing cows with TRP and abomasal ulcer even though at $35 \%$ it was significantly less frequent in cows with U2 than in cows of the other disease groups.

Pale mucous membranes had a low diagnostic sensitivity except for cows with U2 (69\%) and can aid in differentiating these cows from cows with TRP and other types of abomasal ulcer.

Rumen atony is critical for the differentiation of healthy and ill cows because it did not occur in any of the control cows. Surprisingly, it was significantly less frequent in cows with TRP (6\%) than in cows with abomasal ulcer. This was likely because severe changes in demeanour were rarely seen in cows with TRP as opposed to cows with U2 or U4. Marked changes in demeanour significantly affect the gastric centre of the medulla oblongata causing vagalrelated problems with rumen motility. This means that cows with complete rumen atony are highly unlikely to have TRP, perhaps because only severe illnesses with inhibitory inputs, such as fever or severe pain acting on the gastric centre in the medulla oblongata, result in complete cessation of rumen motility [24].

Positive foreign body tests were unsuitable for differentiation of healthy and ill cows as well as of cows of the different disease groups even though positive tests were significantly less frequent in cows with U1 and U2 than in cows with TRP. Of note, only $60 \%$ of the cows with TRP had at least one positive foreign body test. The most likely reason for this is that many cows referred with TRP have been chronically ill and the clinical signs are less distinct than those seen in acute cases [1, 2]. Of interest, the rate of positive foreign body tests in cows with U4 (58\%) and TRP was almost the same and therefore abomasal ulcer must be considered in the differential diagnosis in cows with positive foreign body tests.

Positive percussion and/or ballottement and auscultation on the right side were significantly more frequent in cows with abomasal ulcer than in control cows and cows with TRP, and in cows with U1 than in cows with U2. Overall, a positive test occurred in over $50 \%$ of cows with U1, U4 and U5 but was considerably less frequent in control cows and cows with TRP and U2. 
Black faeces are a crucial variable for distinguishing cows with U2 from healthy cows or from cows with other types of abomasal ulcer, and in cows with U2 had a high diagnostic sensitivity of $80 \%$. Determination of the haematocrit and testing for occult blood are indicated to assess the severity of anaemia and melena in cows passing black faeces.

\section{Conclusions}

The results of our study showed that multiple clinical findings, such as abnormal demeanour, heart rate $>100$ bpm, colic, rumen atony, black faeces, arched back and bruxism, can be used to differentiate healthy cows and those with TRP or abomasal ulcer. Other clinical signs including mild increase in rectal temperature, scleral congestion and a positive reticular foreign body test cannot be used to differentiate healthy cows and those with TRP or abomasal ulcer because they occur in all groups. A detailed history, thorough clinical examination and comprehensive assessment of all available information are needed for a clinical diagnosis.

\section{Abbreviations}

TRP: Traumatic reticuloperitonitis; U1: Abomasal ulcer type-1; U2: Abomasal ulcer type-2; U3: Abomasal ulcer type-3; U4: Abomasal ulcer type-4; U5: Abomasal ulcer type-5; Bpm: Beats per minute; Min: Minute; LR: Positive likelihood ratio; Fig: Figure

\section{Acknowledgements}

The authors thank the agricultural assistants for their help with the clinical examinations.

\section{Authors' contributions}

UB initiated, planned and supervised the study and prepared the manuscript, SW and CR analysed the medical histories of the cows as part of her dissertation, KN, CG and CO made contributions to acquisition and interpretation of data and were involved in drafting the manuscript. All authors read and approved the final manuscript.

\section{Funding}

Not applicable since it was a retrospective analysis of medical records.

\section{Availability of data and materials}

The datasets used and analysed for this study are available from the corresponding author on reasonable request.

\section{Ethics approval and consent to participate}

This study was not submitted for ethics committee review because it is a retrospective analysis of medical records of the Clinic of Ruminants, Vetsuisse Faculty, University of Zurich. All owners signed a consent form allowing us to use the animals and all the associated medical data for scientific analysis and publication.

\section{Consent for publication}

Not applicable.

\section{Competing interests}

The authors declare that they have no competing interests.
Received: 1 February 2020 Accepted: 6 August 2020

Published online: 29 September 2020

\section{References}

1. Dirksen G. Krankheiten von Haube und Pansen beim ruminanten Rind. In: Dirksen G, Gründer HD, Stöber M, editors. Innere Medizin und Chirurgie des Rindes. Berlin: Parey Buchverlag; 2002. p. 396-455.

2. Constable PD, Hinchcliff KW, Done SH, Grünberg W. Diseases of the alimentary tract - ruminant. In: Constable PD, Hinchcliff KW, Done SH, Grünberg W, editors. Veterinary Medicine. A textbook of the diseases of cattle, horses, sheep, pigs, and goats. St. Louis: Elsevier; 2017. p. 436-621.

3. Whitlock RH. Bovine stomach diseases. In: Anderson NV, editor. Veterinary gastroenterology. Philadelphia: Lea and Febiger; 1980. p. 425-8.

4. Smith DF, Munson L, Erb HN. Abomasal ulcer disease in adult dairy cattle. Cornell Vet. 1983;73:213-24.

5. Constable PD. Abomasal ulcers. In: Line S, editor. The Merck veterinary manual. 10th ed. New York: Merck and Co., Inc.; 2010. p. 219-22.

6. Hund A, Wittek T. Abomasal and third compartment ulcers in ruminants and south american camelids. Vet Clin North Am Food Anim Pract. 2018;34:35-54.

7. Munch SL, Nielsen SS, Krogh MA, Capion N. Prevalence of abomasal lesions in Danish Holstein cows at the time of slaughter. J Dairy Sci. 2019;102:5403-9.

8. Braun U, Reif C, Hilbe M, Gerspach C. Type-5 abomasal ulcer and omental bursitis in 14 cows. Acta Vet Scand. 2020;62:4.

9. Ducharme NG, Desrochers A, Fubini SL, Pease AP, Mizer LA, Walker W, Trent AM, Roy JP, Rousseau M, Radcliffe RM, Steiner A. Surgery of the bovine digestive system. In: Fubini SL, Ducharme NG, editors. Farm animal surgery. Philadelphia: Saunders Elsevier; 2017. p. 223-343.

10. Braun U, Warislohner S, Torgerson P, Nuss K, Gerspach C. Clinical and laboratory findings in 503 cattle with traumatic reticuloperitonitis. BMC Vet Res. 2018;14:66.

11. Braun U, Gerspach C, Reif C, Hilbe M, Nuss K. Clinical, laboratory and ultrasonographic findings in 94 cows with type-1 abomasal ulcer. Schweiz Arch Tierheilk. 2020;162:235-44.

12. Braun U, Gerspach C, Nuss K, Hässig M, Hilbe M, Reif C. Clinical and laboratory findings, treatment and outcome in 145 cows with type-2 abomasal ulcer. Res Vet Sci. 2019;124:366-74.

13. Braun U, Gerspach C, Hilbe M, Devaux DJ, Reif C. Clinical and laboratory findings in 60 cows with type-3 abomasal ulcer. Schweiz Arch Tierheilk. 2019;161:523-31.

14. Braun U, Reif C, Nuss K, Hilbe M, Gerspach C. Clinical, laboratory and ultrasonographic findings in 87 cows with type-4 abomasal ulcer. BMC Vet Res. 2019;15:100.

15. Braun U, Warislohner S, Gerspach C, Ohlerth S, Nuss K. Treatment of 503 cattle with traumatic reticuloperitonitis. Acta Vet Scand. 2018;60:55.

16. Braun U, Amrein E, Estermann U, Egli J, Schweizer T, Lutz H, Ehrensperger F, Vandevelde M, Kihm U. Untersuchungen an 182 Nachkommen von an boviner spongiformer Enzephalopathie (BSE) erkrankten Kühen in der Schweiz. Teil 1: Klinische Befunde. Schweiz Arch Tierheilk. 1998;140:240-9.

17. Braun U, Beckmann C, Gerspach C, Hässig M, Muggli E, Knubben-Schweizer G, Nuss K. Clinical findings and treatment in cattle with caecal dilatation. BMC Vet Res. 2012:8:75.

18. Petrie A, Watson P. Additional techniques. In: Petrie A, Watson P, editors. Statistics for veterinary and animal science. Chichester: Wiley-Blackwell; 2013. p. 200-29.

19. Smith DF, Munson L, Erb HN. Predictive values for clinical signs of abomasal ulcer disease in adult dairy cattle. Prev Vet Med. 1986;3:573-80.

20. Rosenberger G. Clinical examination of cattle. Berlin, Hamburg: Paul Parey; 1990

21. Gay CC, Radostits OM. Clinical examination of the cardiovascular system. In: Radostits OM, Mayhew IGJ, Houston DM, editors. Veterinary clinical examination and diagnosis. London: WB Saunders; 2000. p. 245-91.

22. Radostits OM. Clinical examination of cattle and calves. In: Radostits OM, Mayhew IGJ, Houston DM, editors. Veterinary clinical examination and diagnosis. London: WB Saunders; 2000. p. 151-77.

23. Dirksen G. Forestomachs. In: Rosenberger G, editor. Clinical examination of cattle. Hamburg, Berlin: Paul Parey; 1979. p. 197-220.

24. Constable PD, Hoffsis GF, Rings DM. The reticulorumen: Normal and abnormal motor function. Part I. primary contraction cycle. Compend Contin Educ Pract Vet. 1990;12:1008-15.

\section{Publisher's Note}

Springer Nature remains neutral with regard to jurisdictional claims in published maps and institutional affiliations. 